\title{
Variantes quirúrgicas en el tratamiento de la desinserción proximal de isquiotibiales. Reporte de cuatro casos tratados con cirugía
}

\author{
Franco L. De Cicco, Fernando Holc, Javier E. Sánchez Saba, Danilo Taype Zamboni, Jorge D. Barla, \\ Carlos F. Sancineto, Guido Carabelli \\ Sector de Trauma, Instituto de Ortopedia y Traumatología "Prof. Dr. Carlos E. Ottolenghi”, Hospital Italiano de Buenos Aires, \\ Ciudad Autónoma de Buenos Aires, Argentina
}

\section{RESUMEN}

Las lesiones por avulsión isquiática o rotura tendinosa en la inserción proximal de los isquiotibiales son infrecuentes. El abordaje terapéutico es diferente del de los desgarros. Se ha comprobado ampliamente un mayor beneficio con el tratamiento quirúrgico y, dada la baja frecuencia de este tipo de lesiones, son pocos los cirujanos ortopédicos habituados tanto al diagnóstico como al procedimiento quirúrgico. El objetivo de este estudio es reportar cuatro casos de pacientes con rotura insercional de isquiotibiales y describir la técnica quirúrgica utilizada. Asimismo, se detallan las variantes quirúrgicas y sus resultados.

Palabras clave: Isquiotibiales; reparación quirúrgica; resultado funcional; deporte.

Nivel de Evidencia: IV

\section{Surgical Variants in the Treatment of Proximal Hamstring Avulsion}

\section{ABSTRACT}

Proximal tendon avulsion of the hamstring insertion is a rare entity. The therapeutic approach is different in contrast to the treatment in common muscle tears. The greater benefit of surgical treatment has been widely verified in the literature, and given the low frequency of this type of injury, few orthopedic surgeons are used to both diagnosis and surgical procedures in this anatomical region. The aim of this article is to report four patients with insertional hamstring rupture and describe the surgical technique used in each case. We present the surgical variants as well as the outcomes achieved.

Keywords: Hamstrings; surgical treatment; functional outcome; sports.

Level of Evidence: IV

\section{INTRODUCCIÓN}

La lesión muscular de los isquiotibiales constituye una de las lesiones más frecuentes en deportistas. ${ }^{1,2}$ No obstante, la avulsión isquiática o rotura tendinosa en su inserción proximal es infrecuente, tiene una incidencia inferior al $5 \%$ de todas las lesiones deportivas. ${ }^{3,4}$

El abordaje terapéutico es diferente, la tendencia en los desgarros es hacia el tratamiento conservador, en tanto que, para la rotura insercional de isquiotibiales, se ha comprobado ampliamente el mayor beneficio del tratamiento quirúrgico..$^{5-8}$ Dada la baja frecuencia de este tipo de lesiones, son pocos los cirujanos ortopédicos habituados a los procedimientos quirúrgicos en dicha región anatómica. ${ }^{9}$

Las complicaciones de no tratar una rotura insercional de isquiotibiales abarcan desde el dolor crónico, ${ }^{10}$ la pérdida funcional deportiva significativa ${ }^{4,11}$ hasta la irritación del nervio ciático. ${ }^{10}$ Esto último debido a la íntima 
relación de dicha masa muscular con este nervio, en donde, al retraerse las fibras musculares, se produce una fibrosis que podría irritarlo, causando así un "síndrome isquiotibial”, diagnóstico diferencial dentro de las ciatalgias. $^{12}$

El objetivo de este artículo es comunicar cuatro casos de pacientes con rotura insercional de isquiotibiales y describir la técnica quirúrgica utilizada con sus variantes. Se exponen los resultados obtenidos a largo plazo.

\section{CASOS CLÍNICOS}

\section{Caso 1}

Hombre de 44 años, sin antecedentes patológicos, deportista recreativo quien, durante un partido de fútbol, siente un dolor súbito en el muslo derecho tras una barrida en el campo de juego. Mediante una ecografía, se le diagnostica una disrupción fibrilar en relación con el músculo semitendinoso de $34 \mathrm{~mm}$, con hematoma adyacente de $21 \mathrm{~mm}$. A los tres meses, vuelve a consultar por la persistencia del dolor con limitación funcional sin déficit neurológico. Se realiza una resonancia magnética (RM) que muestra una desinserción proximal de isquiotibiales con retracción de aproximadamente $50 \mathrm{~mm}$. Se indica reparación quirúrgica.

Cirugía: Abordaje longitudinal posterior de muslo. Reparación primaria con arpones del tendón conjunto.

A los tres años, mediante un momento de contracción excéntrica descargando peso en el trabajo, sufre una nueva dolencia isquiática. La ecografía revela una lesión incompleta del músculo semitendinoso. Se decide la reintervención.

Cirugía: Abordaje longitudinal posterior extendido sobre la cicatriz previa. Se constata una lesión del músculo semitendinoso en la unión miotendinosa. Se realiza una liberación proximal del músculo y se prepara la superficie de anclaje en el isquion. Dicho anclaje se efectúa con dos arpones de $5 \mathrm{~mm}$ doble sutura. Con este medio se realiza la sutura del cabo distal de la rotura miotendinosa aproximándola hacia la entesis y el isquion, generando, de esta manera, una recuperación de la tensión muscular.

\section{Caso 2}

Mujer de 54 años, sin antecedentes patológicos, deportista recreativa quien, durante un partido de tenis, siente un dolor súbito en el glúteo derecho posterior a un arranque en velocidad. Consulta inmediatamente en la Guardia, donde se constata un hematoma extenso en la cara posterior del muslo, dolor a la palpación del isquion sin brecha visible o palpable. En las radiografías, no se observan lesiones óseas asociadas. La ecografía muestra una rotura completa insercional proximal de los tendones isquiotibiales derechos, con retracción distal aproximada de $4 \mathrm{~mm}$. La RM a los cuatro días revela una desinserción tendinosa de $47 \mathrm{~mm}$. Se decide la resolución quirúrgica.

Cirugía: Abordaje transversal sobre el pliegue glúteo. Reparación primaria con arpones del tendón conjunto.

\section{Caso 3}

Mujer de 52 años, con antecedentes de colectomía total por cáncer de colon, sin enfermedad residual. Consulta con diagnóstico de desinserción completa del tendón proximal de isquiotibiales derechos. Había sufrido un trauma deportivo indirecto una semana antes de la consulta. Tanto la ecografía musculoesquelética como la RM de muslo derecho informan una retracción tendinosa hacia caudal de $6 \mathrm{~cm}$. Se decide realizar un tratamiento quirúrgico.

Cirugía: Abordaje longitudinal posterior de muslo. Reparación primaria con arpones de ambos tendones.

\section{Caso 4}

Mujer de 43 años, sin antecedentes patológicos, maratonista, que sufre una caída desde su propia altura con el miembro inferior derecho en extensión de rodilla y flexión de cadera. Consulta por dolor posterior de muslo con irradiación a la pierna que se exacerba al extender la rodilla. Se realiza una ecografía musculoesquelética que muestra una rotura completa de la unión miotendinosa proximal del semimembranoso y desgarro total del tendón conjunto. La RM de muslo derecho muestra una retracción tendinosa hacia caudal de aproximadamente $6 \mathrm{~cm}$ (Figura 1). Se decide el tratamiento quirúrgico.

Cirugía: Abordaje transversal sobre el pliegue glúteo. Reparación primaria con arpones del tendón conjunto. 


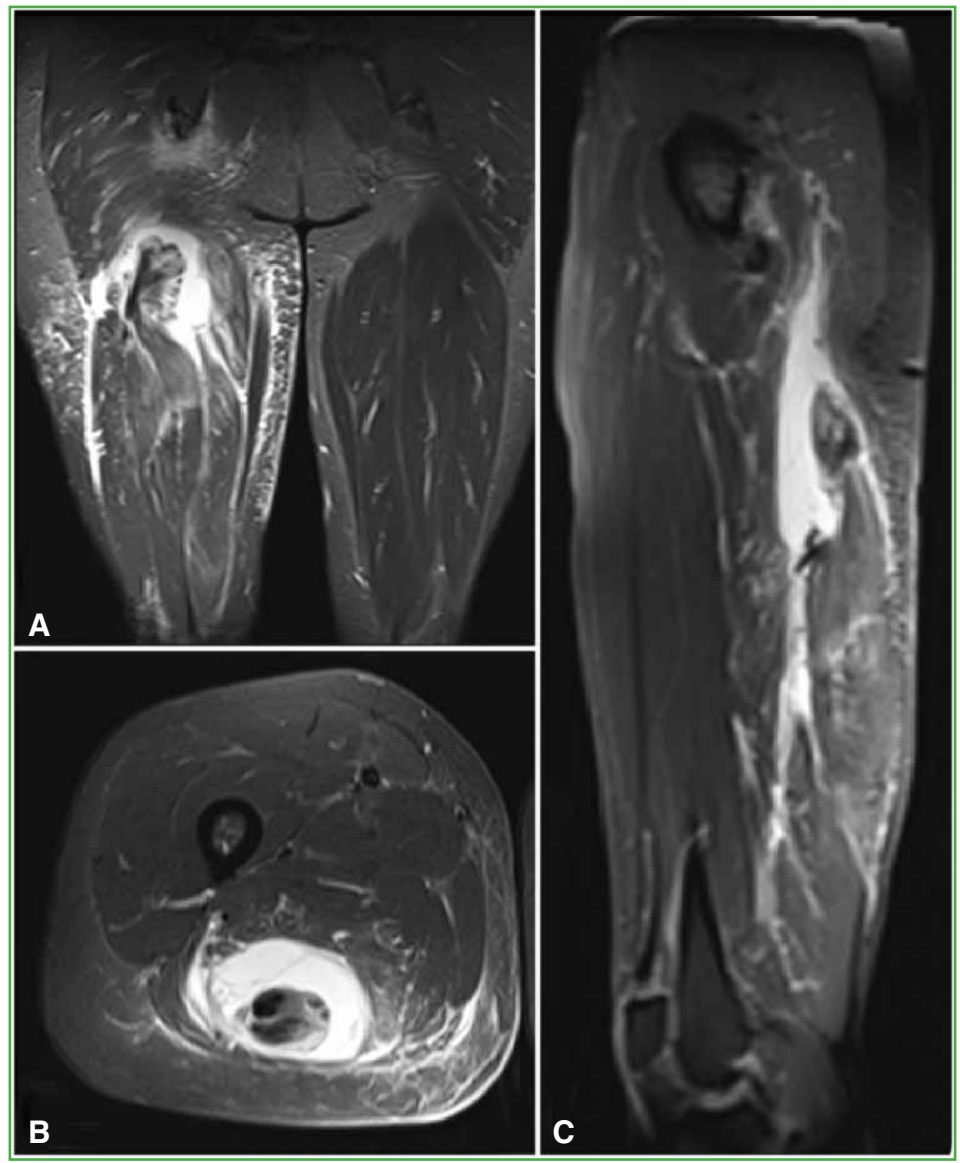

Figura 1. Resonancia magnética de muslo derecho. A. Corte coronal. B. Corte axial. C. Corte sagital. Lesión y retracción tendinosas.

\section{Técnica quirúrgica general}

Se ubica al paciente en decúbito ventral protegiendo las prominencias óseas. El abordaje depende de las características del paciente. En personas delgadas y con lesiones agudas sin retracción tendinosa, optamos por un abordaje en el pliegue glúteo (Figura 2A). Este abordaje plantea dificultades para realizar la reinserción, pero es más estético. En pacientes con gran panículo adiposo o casos crónicos con retracción tendinosa, optamos por un abordaje posterior perpendicular al pliegue glúteo con extensión distal de 12-15 cm (Casos 1 y 3) (Figura 2B).

En el plano profundo, se identifican, mediante disección roma, el nervio ciático mayor, el isquion denudado de las inserciones tendinosas y el cabo tendinoso desinsertado. Se reseca la fibrosis hasta lograr un lecho adecuado en el isquion para la colocación de los arpones. Se colocan entre dos y cinco arpones, según necesidad, hasta lograr el apoyo del conjunto tendinoso sobre el hueso. Recomendamos colocar, al menos, tres arpones en el isquion (distal, medio y proximal). El más distal se sutura a $5 \mathrm{~cm}$ del cabo del conjunto tendinoso, mientras que el más proximal, cercano al cabo tendinoso permitiendo la aposición del tendón de manera equidistante sobre su inserción ósea. La sutura tendinosa se realiza mediante la técnica de Krackow (Figura 3). Se posiciona el miembro inferior en flexión de rodilla a $90^{\circ}$ para relajar las estructuras musculares del compartimento posterior.

Finalizada la reinserción tendinosa, se procede al cierre por planos manteniendo la flexión de rodilla. Se debe mantener esta posición en el posoperatorio mediante una férula.

\section{Protocolo de rehabilitación}

En nuestra institución, el protocolo de rehabilitación posoperatoria consistió en inmovilización con férula en flexión de rodilla sin carga del miembro intervenido. Las primeras dos semanas a $90^{\circ}$, la tercera y cuarta semanas a $60^{\circ}$, la quinta y sexta semanas a $45^{\circ}$ con apoyo parcial (Figura 4 ). 


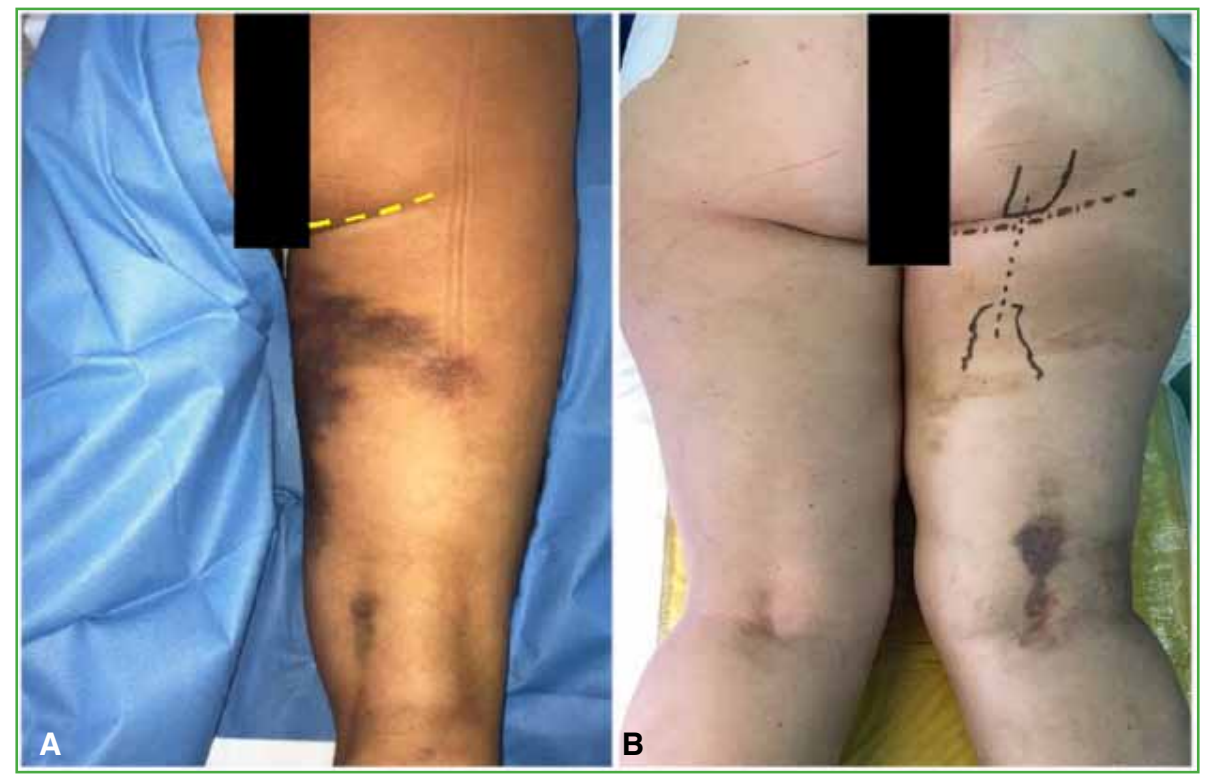

Figura 2. A. Hematoma posterior de muslo y delineado de la incisión a través del pliegue glúteo. B. Delineado de incisión longitudinal.
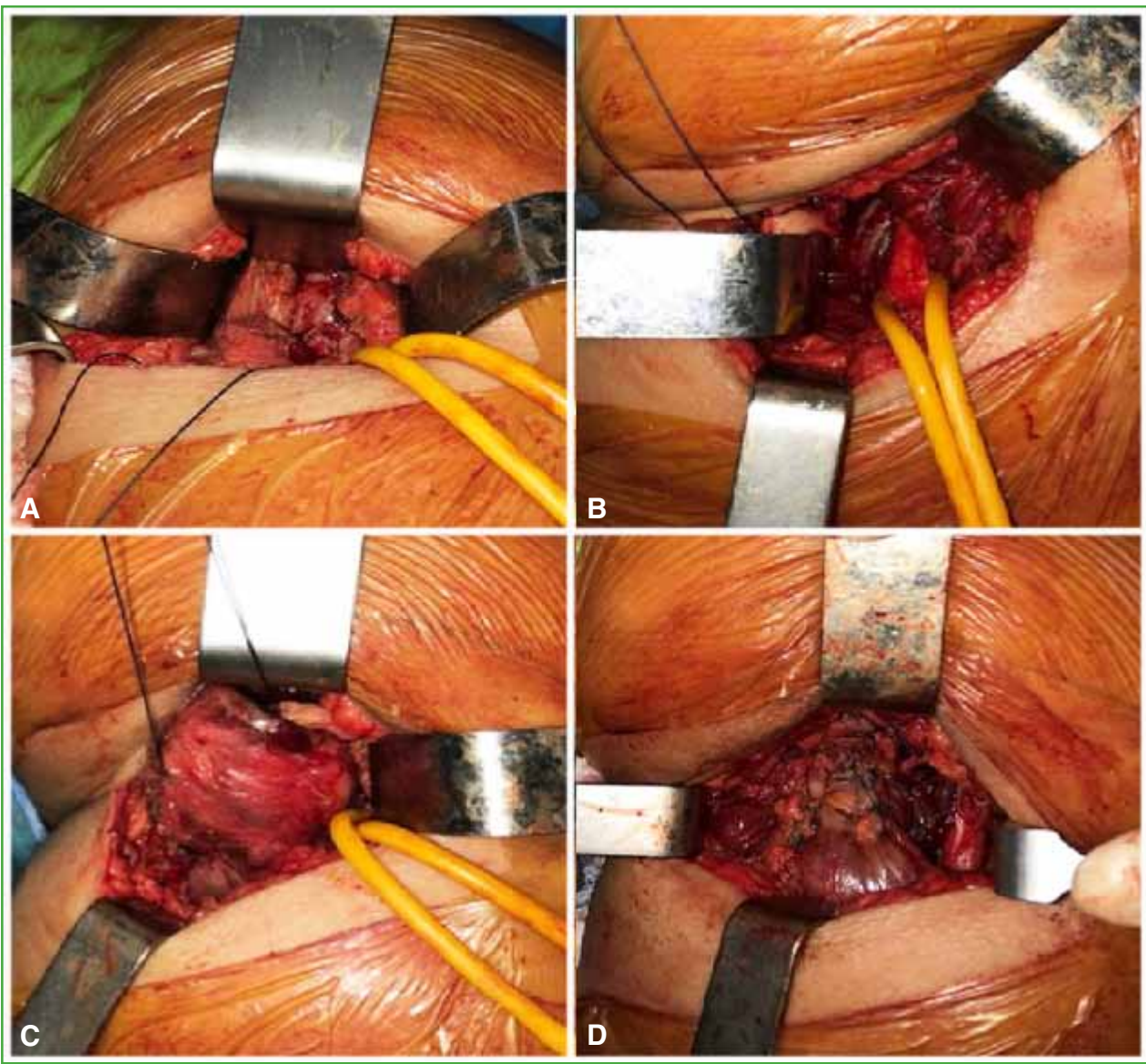

Figura 3. Imágenes clínicas intraoperatorias. A. Isquion denudado de las inserciones tendinosas. B. Reparo de nervio ciático común. C. Tendón conjunto llevado a su posición anatómica. D. Reparación final con arpones. 


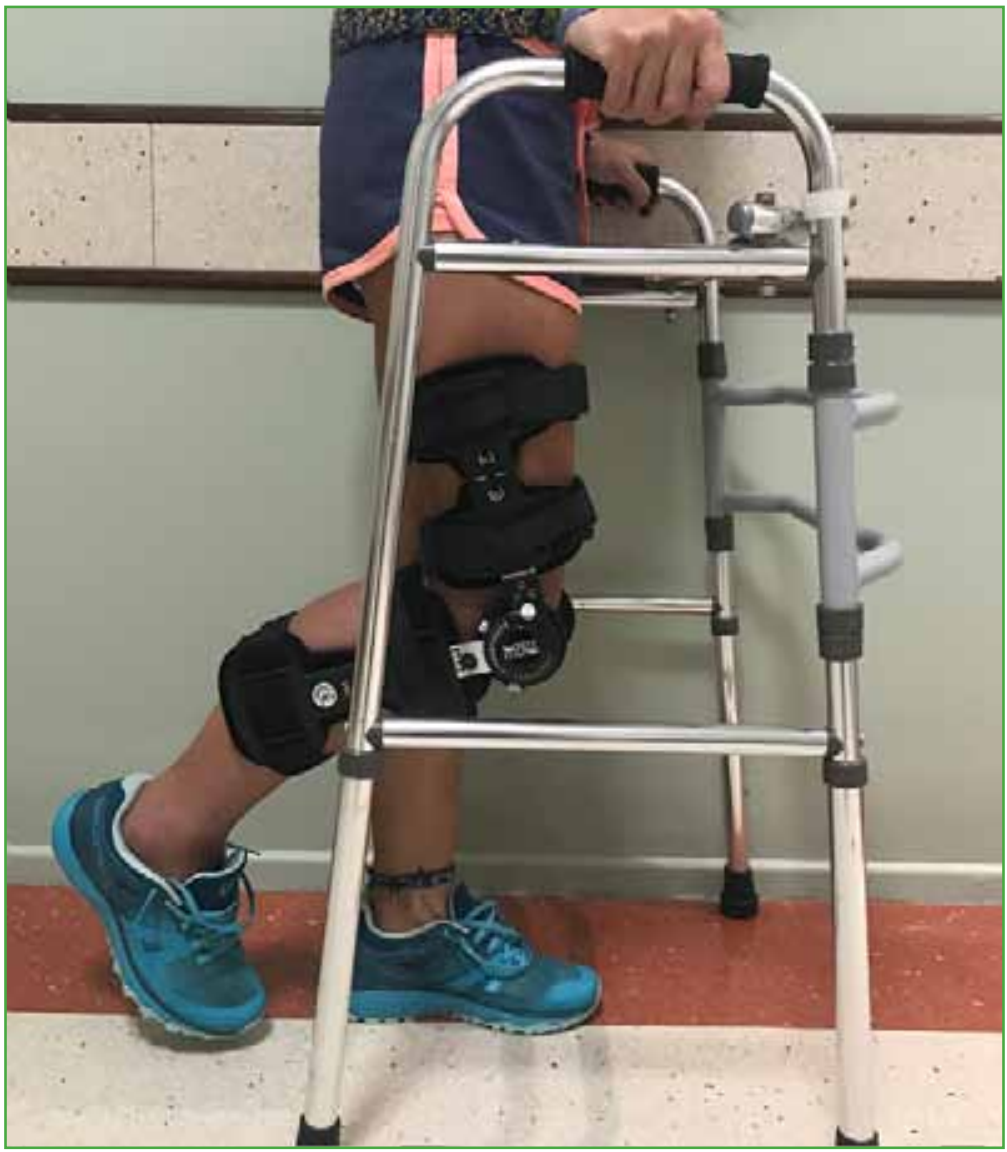

Figura 4. Imagen clínica del paciente en el posoperatorio. Férula de ángulo fijo variable.

Según las recomendaciones publicadas, a las seis semanas, se inicia la carga total con el miembro afectado. ${ }^{13}$ Tras las seis semanas, indicamos el retiro del inmovilizador y permitimos la carga completa del miembro operado. Desde la sexta semana, comienza la rehabilitación específica. Se indica comenzar con ejercicios de extensión y flexión activa y pasiva de cadera y rodilla mediante ejercicios isotónicos y ejercicios de cadena cerrada. Luego se continúa con ejercicios de cadena abierta que permiten mejorar y comenzar a recuperar la fuerza. ${ }^{13}$ Cabe destacar que el fortalecimiento es un factor necesario no solo para la rehabilitación, sino también para la prevención de la recidiva de la lesión.

A las 12 semanas, se inicia la actividad deportiva protegida, sobre terrenos firmes y con marcha lineal.

\section{RESULTADOS}

No se registraron complicaciones intraoperatorias asociadas al procedimiento. Ningún paciente tuvo complicaciones relacionadas con la herida ni tuvo que ser reintervenido antes de los 12 meses de la cirugía. No hubo casos de dolor posoperatorio (escala analógica visual: 0/10).

El rango de movilidad del miembro comparado con el contralateral fue completo. Todos los pacientes estuvieron satisfechos con los resultados funcionales obtenidos al finalizar la rehabilitación. Si bien ninguno era deportista de alto rendimiento, todos practicaban actividad física recreativa (tenis y fútbol) más de cuatro veces por semana. Antes de los ocho meses posteriores a la cirugía, retomaron la actividad deportiva. Tres de los cuatro pacientes volvieron a practicar la actividad deportiva completa sin déficit, como antes de la lesión. El seguimiento mínimo fue de dos años. 


\section{DISCUSIÓN}

La masa muscular de los isquiotibiales está comprendida por tres músculos, el semimembranoso, el semitendinoso y el bíceps femoral con sus dos porciones (larga y corta). Se inserta a proximal en el isquion por medio de dos tendones (Figura 5). Un tendón conjunto entre el semitendinoso y la porción larga del bíceps femoral conforma una inserción oval. ${ }^{9}$ Estos se separan en dos cabos individualizados aproximadamente a $9 \mathrm{~cm}$. Lateral a este complejo oval, se presenta la inserción del tendón del semimembranoso de manera independiente. Lateral a las inserciones de los isquiotibiales y a $5 \mathrm{~cm}$ hacia proximal del borde distal del glúteo mayor, se encuentra el paquete vasculonervioso glúteo inferior. El nervio ciático debe identificarse a 1,5 $\mathrm{cm}$ en promedio del reborde lateral de la tuberosidad isquiática. Su función compromete dos articulaciones, la cadera y la rodilla. El semitendinoso y el semimembranoso extienden la cadera cuando el tronco corporal está fijo. Flexionan la rodilla e intrarrotan la pierna cuando la rodilla se encuentra en flexión. La cabeza larga del bíceps femoral extiende la cadera, al iniciar la marcha, y tanto la cabeza corta como la larga flexionan la rodilla y extrarrotan la pierna cuando la rodilla está en flexión.

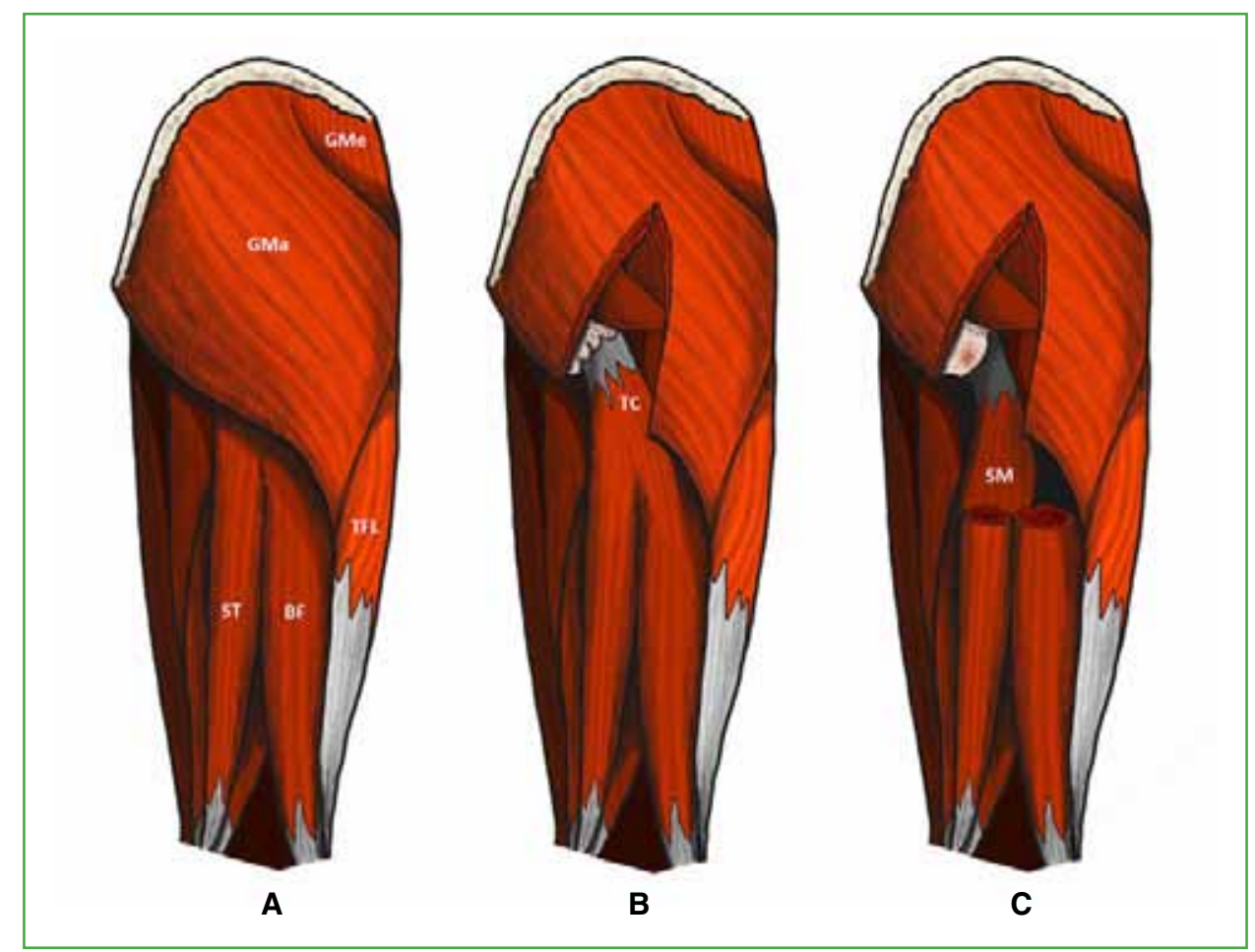

Figura 5. Esquema anatómico por planos de la región posterior del muslo. Músculo glúteo medio (GMe), músculo glúteo mayor (GMa), músculo tensor de la fascia lata (TFL), músculo bíceps femoral (BF), músculo semitendinoso (ST), músculo semimembranoso (SM) y tendón conjunto isquiotibial (TC).

Existen factores de riesgo para la producción de lesiones proximales, entre ellos, las lesiones previas de los músculos isquiotibiales se exponen como el principal factor, también la debilidad y la fatiga musculares, los desequilibrios musculares y las disfunciones lumbopélvicas. ${ }^{14}$

Las lesiones resultan de un estiramiento excesivo a nivel de la unión miotendinosa. Se generan por contracciones con sobrecarga excéntrica, hiperflexión de la cadera e hiperextensión de la rodilla. En cambio, los desgarros del vientre muscular se producen por una contracción concéntrica, por ejemplo, en un esprint. ${ }^{15}$

La principal indicación de estudios por imágenes en las lesiones agudas de los músculos isquiotibiales es el diagnóstico de roturas proximales de su inserción. 
El alcance de las radiografías, si bien es limitado, permite observar avulsiones óseas a nivel de la tuberosidad isquiática. La tomografía computarizada ha quedado relegada por la RM y la ecografía. ${ }^{16}$ Esta última, aunque no cuenta con la precisión de la RM, su practicidad, bajo costo, la ausencia de contraindicaciones y de efectos adversos la convierten en el método de referencia. Permite el análisis muscular y tendinoso, sobre todo en lesiones superficiales, de manera estática y dinámica. Tiene sus limitaciones para las lesiones leves con escaso líquido perilesional o en pacientes con mucho tejido corporal, especialmente en la porción proximal del tendón, donde el músculo glúteo mayor que es multifasciculado y graso dificulta la visualización. ${ }^{16}$

La RM permite detectar desde las lesiones sutiles a las más graves y delimitar su extensión, un factor de relevancia, porque tiene implicancias en el tiempo de rehabilitación. ${ }^{17}$ En lesiones agudas, las secuencias T2 o de supresión grasa (STIR) muestran imágenes de alta intensidad como resultado del edema o la hemorragia que rodea al músculo dañado. En tanto que, en las secuencias T1, se observan áreas de intensidad intermedia que se confunden con la masa muscular. La rotura insercional de isquiotibiales puede ser completa o afectar solo la porción del semimembranoso o al tendón conjunto del semitendinoso y el bíceps femoral. En estas circunstancias, encontraremos una discontinuidad entre el hueso y el tendón remanente (ya sea parcial o completo) que estará rodeado de hematoma o líquido inflamatorio que infiltra también al músculo, en grado variable, dándole un aspecto de "pluma". ${ }^{18}$

Es primordial cuantificar la extensión de la retracción del tendón cuando se opte por un tratamiento quirúrgico y sus relaciones inmediatas con el nervio ciático.

Las lesiones pueden clasificarse según su presentación clínica en tres grados: grado 1 (leve): estiramiento excesivo con pérdida mínima de la integridad de la entesis; grado 2 (moderado): desinserción parcial y grado 3 (severo): rotura total de la entesis. ${ }^{1}$

Wood y cols. propusieron una nueva clasificación (Tabla) en la cual se divide a las lesiones en cinco estadios, según su localización anatómica, el grado de desinserción (completa o incompleta), el grado de retracción muscular y la presencia o no de irritación del nervio ciático. ${ }^{18}$

Tabla. Clasificación de Wood ${ }^{18}$

\begin{tabular}{|l|l|}
\hline Tipo & Característica \\
\hline 1 & Avulsión ósea \\
\hline 2 & Lesión en la unión miotendinosa \\
\hline 3 & Desinserción parcial \\
\hline 4 & Desinserción completa sin retracción \\
\hline 5 & Desinserción completa con retracción \\
\hline $5 B$ & Tipo 5 + irritación del nervio ciático \\
\hline
\end{tabular}

La mayoría de estas lesiones responden al tratamiento conservador con crioterapia, reposo, elongación y retorno gradual a las actividades habituales. Pero, ante casos de desinserciones, se le da una importancia principal al tratamiento quirúrgico ${ }^{1,10,15}$ en deportistas que realizan carreras de velocidad y necesitan acciones musculares explosivas.

Teniendo en cuenta lo expresado, son dos los focos principales de atención frente a estas lesiones: el tipo de tratamiento (quirúrgico vs. conservador) y cuándo realizarlo (agudo vs. crónico).

Históricamente, el tratamiento quirúrgico para reparar lesiones de tendones isquiotibiales no recibía gran atención. Con el tiempo, esto fue cambiando gracias al entendimiento de las lesiones y el entrenamiento ortopédico. ${ }^{19}$

El tratamiento conservador es la principal opción terapéutica frente a lesiones parciales y en tendinopatías insercionales. ${ }^{10,15}$ Sin embargo, en atletas, los resultados no son óptimos, por ello se plantea el tratamiento quirúrgico. Este se recomienda frente a lesiones de dos tendones y desinserciones con retracciones $>2 \mathrm{~cm} .{ }^{4,15} \mathrm{La}$ formación de tejido cicatricial retraído puede inhibir la inervación del tejido de regeneración muscular y reducir su contractilidad y rango de movilidad, así como también irritar el nervio ciático ante la cicatrización perineural. Se ha observado atrofia grasa en los márgenes del músculo avulsionado y una reducción generalizada en el volumen del músculo. ${ }^{20}$ 
Hofmann y cols. evaluaron a pacientes que prefirieron un manejo conservador para las roturas proximales completas de los isquiotibiales, y observaron déficits en la fuerza del miembro afectado y fracaso en el retorno deportivo a su nivel previo. ${ }^{11}$

En revisiones sistemáticas llevadas a cabo por otros autores, se llegó a la conclusión de que la cirugía mejora los resultados en cuanto al retorno deportivo, la fuerza y la resistencia. ${ }^{8,21,22}$

Piposar y cols. también obtuvieron resultados funcionales positivos con una mejoría significativa al comparar pacientes operados y con tratamiento conservador, excepto en la fuerza donde no hallaron diferencias significativas. $^{8,23}$

De todos modos, hay situaciones especiales, entre ellas, las desinserciones parciales que suelen producirse por lesiones repetitivas y crónicas. Tradicionalmente estas lesiones son de tratamiento conservador y se indica la cirugía si no hay mejoría tras seis meses de tratamiento no quirúrgico. ${ }^{8,23}$

En cuanto a la rehabilitación, la actividad deportiva completa puede desarrollarse una vez que la funcionalidad del miembro inferior alcanza un $80 \%$ comparada con la contralateral mediante un estudio isocinético. Además, se puede considerar el retorno al deporte si no hay dolor, el paciente puede realizar las actividades deportivas sin temor, se ha recuperado la fuerza y la elongación del músculo afectado y, por último, si el paciente está en condiciones físicas y tiene la confianza propia necesaria para concretar la actividad específica. En promedio, esto se logra entre los 6 y los 10 meses posteriores a la cirugía. ${ }^{13,24}$

Por otro lado, Hofmann y cols. describen que, en casos de tratamiento conservador, es necesaria la rehabilitación por un lapso mínimo de 16 semanas antes del retorno al deporte. En nuestra serie de casos, ningún paciente recibió tratamiento conservador. Cabe destacar que, con el tratamiento conservador, los índices de satisfacción reportados son bajos y un tercio de los pacientes son incapaces de volver a realizar su actividad deportiva al nivel previo a la lesión. ${ }^{11}$

Respecto de cuándo realizar un procedimiento quirúrgico, en algunos estudios, se sostiene que la cirugía en la etapa aguda mejora la evolución de los pacientes con estas lesiones, determinada por la fuerza, el dolor, el retorno al deporte y la satisfacción. ${ }^{22}$ En cambio, hay otros autores que no hallaron diferencias relacionadas con el momento de la cirugía. ${ }^{6}$

El estudio de Blakeney y cols. apoya la recomendación de tratamiento quirúrgico, en estadio agudo.,25 Sin embargo, consideran que se logran resultados favorables con la cirugía tanto en las lesiones agudas como en las crónicas. El paciente del caso 1 es fiel reflejo de ello.

Las diferencias en la técnica quirúrgica entre las lesiones agudas y crónicas dependen principalmente de la retracción tendinosa, la fibrosis alrededor de la lesión y la necesidad de aumento del tendón remanente. Se ha descrito el uso de aloinjerto de tendón de Aquiles o autoinjerto de fascia lata. ${ }^{6}$

\section{CONSIDERACIONES FINALES}

La desinserción proximal de isquiotibiales es un cuadro de baja frecuencia y son muy pocos los casos en la bibliografía nacional. El tratamiento quirúrgico debe ser considerado una opción válida. En coincidencia con lo detallado en la bibliografía, nuestros pacientes obtuvieron resultados favorables mediante el tratamiento quirúrgico.

Conflicto de intereses: Los autores no declaran conflictos de intereses.

ORCID de F. Holc: https://orcid.org/0000-0002-1224-3312

ORCID de J. E. Sánchez Saba: https://orcid.org/0000-0001-5496-3513

ORCID de D. Taype Zamboni: https://orcid.org/0000-0001-8293-9879
ORCID de J. D. Barla: https://orcid.org/0000-0001-9233-5278

ORCID de C. F. Sancineto: https://orcid.org/0000-0002-5190-4312

ORCID de G. Carabelli: https://orcid.org/0000-0002-7049-0688 


\section{BIBLIOGRAFÍA}

1. Clanton TO, Coupe KJ. Hamstring strains in athletes: diagnosis and treatment. J Am Acad Orthop Surg 1998;6(4):237-48. https://doi.org/10.5435/00124635-199807000-00005

2. Ali K, Leland JM. Hamstring strains and tears in the athlete. Clin Sports Med 2012;31(2):263-72. https://doi.org/10.1016/j.csm.2011.11.001

3. Johnson AE, Granville RR, DeBerardino TM. Avulsion of the common hamstring tendon origin in an active duty airman. Mil Med 2003;168(1):40-2. https://doi.org/10.1093/milmed/168.1.40

4. Gidwani S, Bircher MD. Avulsion injuries of the hamstring origin - a series of 12 patients and management algorithm. Ann R Coll Surg Engl 2007;89(4):394-9. https://doi.org/10.1308/003588407X183427

5. Cohen S, Bradley J. Acute proximal hamstring rupture. J Am Acad Orthop Surg 2007;15(6):350-5. https://doi.org/10.5435/00124635-200706000-00004

6. van der Made AD, Reurink G, Gouttebarge V, Tol JL, Kerkhoffs GM. Outcome after surgical repair of proximal hamstring avulsions: A systematic review. Am J Sports Med 2015;43(11):2841-51. https://doi.org/10.1177/0363546514555327

7. Blakeney WG, Zilko SR, Edmonston SJ, Schupp NE, Annear PT. A prospective evaluation of proximal hamstring tendon avulsions: improved functional outcomes following surgical repair. Knee Surg Sports Traumatol Arthrosc 2017;25(6):1943-50. https://doi.org/10.1007/s00167-017-4475-0

8. Bodendorfer BM, Curley AJ, Kotler JA, Ryan JM, Jejurikar NS, Kumar A, et al. Outcomes after operative and nonoperative treatment of proximal hamstring avulsions: a systematic review and meta-analysis. Am J Sports Med 2018;46(11):2798-808. https://doi.org/10.1177/0363546517732526

9. Miller SL, Gill J, Webb GR. The proximal origin of the hamstrings and surrounding anatomy encountered during repair. A cadaveric study. J Bone Joint Surg Am 2007;89(1):44-8. https://doi.org/10.2106/JBJS.F.00094

10. Bowman KF, Cohen SB, Bradley JP. Operative management of partial-thickness tears of the proximal hamstring muscles in athletes. Am J Sports Med 2013;41(6):1363-71. https://doi.org/10.1177/0363546513482717

11. Hofmann KJ, Paggi A, Connors D, Miller SL. Complete avulsion of the proximal hamstring insertion: functional outcomes after nonsurgical treatment. J Bone Joint Surg Am 2014;96(12):1022-5. https://doi.org/10.2106/JBJS.M.01074

12. Puranen J, Orava S. The hamstring syndrome. A new diagnosis of gluteal sciatic pain. Am J Sports Med 1988;16(5):517-21. https://doi.org/10.1177/036354658801600515

13. Ahmad CS, Redler LH, Ciccotti MG, Maffulli N, Longo UG, Bradley J. Evaluation and management of hamstring injuries. Am J Sports Med 2013;41(12):2933-47. https://doi.org/10.1177/0363546513487063

14. de Hoyo M, Naranjo-Orellana J, Carrasco L, Sañudo B, Jiménez Barroca JJ, Domínguez-Cobo S. Revisión sobre la lesión de la musculatura isquiotibial en el deporte: factores de riesgo y estrategias para su prevención. Rev Andal Med Deporte 2013;6(1):30-7. https://doi.org/10.1016/S1888-7546(13)70032-7

15. Moatshe G, Chahla J, Vap AR, Ferrari M, Sanchez G, Mitchell JJ, et al. Repair of proximal hamstring tears: A surgical technique. Arthrosc Tech 2017;6(2):e311-7. https://doi.org/10.1016/j.eats.2016.10.004

16. Linklater JM, Hamilton B, Carmichael J, Orchard J, Wood DG. Hamstring injuries: anatomy, imaging, and intervention. Semin Musculoskelet Radiol 2010;14(2):131-61. https://doi-org/10.1055/s-0030-1253157

17. Davis KW. Imaging of the hamstrings. Semin Musculoskelet Radiol 2008;12(1):28-41. https://doi.org/10.1055/s-2008-1067935

18. Wood DG, Packham I, Trikha SP, Linklater J. Avulsion of the proximal hamstring origin. J Bone Joint Surg Am 2008;90(11):2365-74. https://doi.org/10.2106/JBJS.G.00685

19. Guanche CA. Hamstring injuries. J Hip Preserv Surg 2015;2(2):116-22. https://doi.org/10.1093/jhps/hnv026

20. Silder A, Heiderscheit BC, Thelen DG, Enright T, Tuite MJ. MR observations of long-term musculotendon remodeling following a hamstring strain injury. Skeletal Radiol 2008;37(12):1101-9. https://doi.org/10.1007/s00256-008-0546-0

21. Matsuda DK. Editorial commentary: proximal hamstring syndrome: another pain in the buttock. Arthroscopy 2018;34(1):122-5. https://doi.org/10.1016/j.arthro.2017.08.260

22. Harris JD, Griesser MJ, Best TM, Ellis TJ. Treatment of proximal hamstring ruptures - a systematic review. Int J Sports Med 2011;32(7):490-5. https://doi.org/10.1055/s-0031-1273753 
23. Piposar JR, Vinod AV, Olsen JR, Lacerte E, Miller SL. High-grade partial and retracted $(<2 \mathrm{~cm})$ proximal hamstring ruptures: nonsurgical treatment revisited. Orthop J Sports Med 2017;5(2):2325967117692507. https://doi.org/10.1177/2325967117692507

24. Birmingham P, Muller M, Wickiewicz T, Cavanaugh J, Rodeo S, Warren R. Functional outcome after repair of proximal hamstring avulsions. J Bone Joint Surg Am 2011;93(19):1819-26. https://doi.org/10.2106/JBJS.J.01372

25. Orava S, Kujala UM. Rupture of the ischial origin of the hamstring muscles. Am J Sports Med 1995;23(6):702-5. https://doi.org/10.1177/036354659502300612 